\title{
BMJ Open Risk of long-term benzodiazepine and Z- drug use following the first prescription among community-dwelling adults with anxiety/mood and sleep disorders: a retrospective cohort study
}

\author{
Jaden Brandt, ${ }^{1}$ Donica Janzen, ${ }^{1}$ Silvia Alessi-Severini, ${ }^{1}$ Alexander Singer, ${ }^{2}$ \\ Dan Chateau, ${ }^{3}$ Murray Enns, ${ }^{4}$ Christine Leong (i) ${ }^{1,4}$
}

To cite: Brandt J, Janzen D, Alessi-Severini S, et al. Risk of long-term benzodiazepine and Z-drug use following the first prescription among community-dwelling adults with anxiety/mood and sleep disorders: a retrospective cohort study. BMJ Open 2021;11:e046916. doi:10.1136/ bmjopen-2020-046916

- Prepublication history and additional supplemental material for this paper are available online. To view these files, please visit the journal online (http://dx.doi.org/10.1136/ bmjopen-2020-046916)

Received 12 November 2020 Accepted 19 October 2021

\section{Check for updates}

(c) Author(s) (or their employer(s)) 2021. Re-use permitted under CC BY-NC. No commercial re-use. See rights and permissions. Published by BMJ.

${ }^{1}$ College of Pharmacy, University of Manitoba, Winnipeg,

Manitoba, Canada

${ }^{2}$ Family Medicine, University of Manitoba, Winnipeg, Manitoba Canada

${ }^{3}$ Manitoba Centre for Health Policy, Winnipeg, Manitoba, Canada

${ }^{4}$ Psychiatry, Univeristy of Manitoba, Winnipeg, Manitoba, Canada

Correspondence to

Dr Christine Leong;

christine.leong@umanitoba.ca

\section{ABSTRACT}

Objective To measure the incidence of long-term benzodiazepine receptor agonist (BZRA) use among individuals with anxiety, mood and/or sleep disorders. To identify factors associated with long-term use following the first prescription.

Methods This was a population-based retrospective cohort study using administrative databases in Manitoba, Canada. Individuals with anxiety/mood or sleep disorder who received their first BZRA between 1 April 2001 and 31 March 2015 were included. Long-term use was defined as $\geq 180$ days. Logistic regression modelling was used to examine predictors of long-term use.

Results Among 206933 individuals included, long-term BZRA use in the first episode of use was $4.5 \%(\geq 180$ days) following their first prescription. Factors associated with $\geq 180$ days of use included male sex (adjusted OR (aOR) 1.33, 95\% Cl 1.27 to 1.39), age $\geq 65$ (aOR 5.15, $95 \% \mathrm{Cl} 4.81$ to 5.52 ), income assistance (aOR $1.68,95 \% \mathrm{Cl}$ 1.55 to 1.81), previous non-BZRA psychotropic (aOR 1.93, $95 \% \mathrm{Cl} 1.83$ to 2.02 ) or opioid use (aOR $1.16,95 \% \mathrm{Cl} 1.11$ to 1.22 ), high comorbidity (aOR $1.43,95 \% \mathrm{Cl} 1.32$ to 1.55 ), high healthcare use (aOR 1.46, 95\% $\mathrm{Cl} 1.33$ to 1.60 ) and psychiatrist prescriber (aOR $2.11,95 \% \mathrm{Cl} 1.93$ to 2.32). Conclusions Less than 1 in 20 patients use BZRAs $\geq 180$ days in their first treatment episode. Several factors were associated with long-term use following the first prescription and further investigation into whether these factors need to be considered at the point of prescribing is warranted. In light of these findings, future research should examine the predictors of cumulative repeat episodes of BZRA exposure.

\section{INTRODUCTION}

The use of benzodiazepine receptor agonists (BZRAs), benzodiazepines (BZD) and Z-Drugs, in the treatment of anxiety and insomnia has shifted based on the evolving data on safety risks and limited efficacy on long-term use in the literature. ${ }^{1-4}$ On their initial introduction into clinical practice in the late 1960s, BZD were considered to be

\section{Strengths and limitations of this study}

- This study used administrative data from the Manitoba Centre for Health Policy, which is one of the most comprehensive datasets in North America containing $>140$ deidentified linked datasets on healthcare, education, social/families, justice and registries for all residents of Manitoba (population of 1.4 million people) not restricted by age or income.

- All diagnoses are identified through physician claims data or hospitalisations, which are dependent on people seeking treatment and may be prone to some misclassification. Drug information is also based on dispensing records from community pharmacies and does not confirm the patient actually took the drug. However, we performed multiple sensitivity analyses to address this.

- The databases do not capture participation in psychological interventions such as cognitive-behavioural therapy.

a safer alternative to barbiturates. ${ }^{5}$ However, safety concerns such as psychomotor impaired accidents (ie, falls and motor-vehicle accidents), dependency and misuse/abuse are now well known. ${ }^{6-8}$ Recent studies have also raised concerns proposing possible links to dementia, recurrence of mood episode, respiratory disease exacerbation and suicide with long-term BZRA use. ${ }^{9-13}$ However, the association of BZRA use for these newer harms is uncertain given conflicting evidence and confounding in previous studies. ${ }^{14}$

In spite of ongoing adverse effect concerns, justification for less restrictive BZRA use have stemmed from their clinical utility as rapidly effective anxiolytic sedatives. ${ }^{15}$ Some view that limiting BZRA use is at times impractical. ${ }^{16}$ Moreover, the use of alternative pharmacotherapy, including trazodone, atypical 
antipsychotics, barbiturates, and tricyclic antidepressants are not without adverse effects. It should also be noted that the difficulties with de-prescribing BZRAs reported in the literature have added caution to the initiation of these agents in practice. ${ }^{417}$

Previous studies examining the pattern of BZRA use have found a decline in benzodiazepine (particularly lorazepam) incident use and an increase in the incidence of Z-drug use. ${ }^{18}{ }^{19}$ Limited studies have examined predictors of long-term use after a first prescription. ${ }^{2021}$ As such, this study sought (i) to measure the incidence of long-term BZRA use among a cohort of community-dwelling Canadian adults with anxiety, mood and/or sleep disorders, and (ii) to determine factors associated with progression to long-term BZD use following the first prescription in this population.

\section{METHODS}

\section{Study design and data sources}

This was a retrospective, cohort study using routinely collected administrative healthcare data pertaining to prescription drug dispensations, outpatient physician claims, hospitalisation discharge abstracts, income assistance records and prescriber demographics (online supplemental table A1). All data used was extracted from the Manitoba Centre for Health Policy Population Research Data Repository. The Repository provides comprehensive coverage of all Manitoba residents contact with the primary healthcare system. The Drug Programme Information Network (DPIN) provides information on outpatient prescription drugs dispensed in Manitoba with the exception of medications dispensed in hospital and nursing stations. In Manitoba, eligible outpatient prescriptions are $100 \%$ covered for residents after an income-based deductible is paid for each fiscal year. DPIN captures information on the drug name, strength, quantity, day-supply, and date of all outpatient prescriptions dispensed regardless of coverage. Merging of the various data sources was facilitated via linkage of unique de-identified Personal Health Information Numbers. The Charlson Comorbidity Score (0 (lowest risk), 1, $\geq 2$ (high risk)) was also determined to examine the effects of comorbidity of duration of use. This was determined based on 17 categories of comorbidities using ICD-9-CM or ICD-10-CA equivalent codes in administrative data to provide the weight-based adjusted risk of death or resource use. ${ }^{22}$

\section{Cohort inclusion/exclusion criteria}

Eligible patients were adults age 18 years and older who initiated a new benzodiazepine or Z-drug prescription (defined as no use in the 1 year prior to the first prescription $^{2021}$ between 1 April 2001 and 31 March 2015, with no preceding dispensations from 1 April 2000 to 31 March 2001 (first year of the dataset) to avoid prevalent user bias (figure 1). All individuals with at least 1 year of registry coverage prior to and after the first prescription was

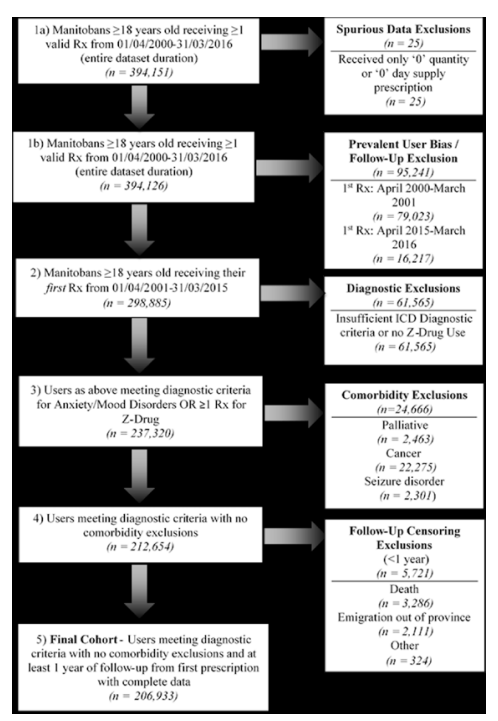

Figure 1 Flow chart of study population. ICD, International Classification of Diseases.

required for cohort inclusion. As such, individuals who received a benzodiazepine in the distant past could be included in the cohort as a new user, provided that the benzodiazepine was not used in the past 1 year. A sensitivity analysis was also performed in which incident use was defined as no prescription for a BZRA was received in the 3 years prior to the first prescription. ${ }^{23}$

Eligibility was also based on diagnostic criteria for anxiety/mood-related disorders and/or insomnia based on International Classification of Diseases 9, Clinical Modification (ICD-9-CM) or International Classification of Diseases 10, Canadian Enhancements (ICD-10-CA) medical claims, either at outpatient physician visits or hospitalisations, occurring within a 5-year period prior to the first prescription. The ICD diagnostic criteria chosen are a combination of the definitions from two sources; the Canadian Public Health Association on mental health surveillance and the MCHP concept dictionary, which listed the various past-case definitions employed in previous research within Manitoba for mood and anxiety disorders (online supplemental table A2). ${ }^{24-28}$ Lastly, because reliance on ICD codes is expected (and has been previously shown) to underestimate capture of sleep disorder cases, we also accepted receipt of a Z-drug in the definition for insomnia as this was their sole approved indication. $^{29}$

To reduce confounding, we established cohort exclusion criteria that otherwise may have justified long-term use of BZDs in clinical scenarios beyond the scope of general guideline recommendations for anxiety and insomnia. Namely, patients were excluded if they had $\geq 1$ ICD code for cancer, a seizure disorder or if there was placement in the Manitoba palliative care drug programme at any point in the 5 years preceding their first prescription for a BZRA (online supplemental table A3). Where patients became palliative $\geq 1$ year after the initial BZRA dispensation, their ongoing use of BZRA was 
censored beginning from the date of their placement, but all use prior to their palliative status was retained. Clobazam use was excluded entirely from the evaluated drug claims because it is approved only as an adjunctive agent for epilepsy in Canada. Finally, patients were excluded if they lacked at least 1 year of registry coverage from their first-prescription index date. This was to eliminate any biasing effect from early mortality, moving out of province or other lost to follow-up.

\section{Main outcome measures}

Long-term use was defined as $\geq 180$ days based on the recommendation from a previous systematic review of similar studies. ${ }^{24}$ This duration is longer than clinical practice guideline duration recommendations and is believed to be of sufficient length for risk of dependence to occur. ${ }^{30}$ One-third of individuals who use BZDs for longer than 6 months have been previously reported to be unable to stop completely due to withdrawal symptoms (eg, anxiety, insomnia, muscle spasms) ${ }^{30}$ A sensitivity analysis, ranging from 60 to 365 days, was also used in our study to account for varying definitions of long-term use reported in the literature. ${ }^{24}$

Patients were followed forward in time from the date of their first BZRA prescription. BZRA 'use episodes' were determined according to consecutive prescription overlap based on dispensation dates and coded day supply values. The allowable gap between prescriptions was the greater of either 30 days or $50 \%$ of the last prescription day supply after the prescription end date (end date $=$ dispensation date+day-supply) of the prior prescription. This gap was chosen to account for those who regularly or frequently used 'as needed' BZRA in the 'use episode' duration. The episode end date was calculated as the date of the last prescription in a given 'use episode' plus its associated day-supply. To account for immeasurable time bias, hospitalisation time was assumed to be a continuation of BZD use given that in-patient drug use data was limited. ${ }^{31}$ The provincial drug programme subsidises dispensations of up to a 100 day-supply.

Individuals were able to have multiple use episodes over the entire study duration. First episode duration and average episode duration were calculated for each user. If patients only had one use episode both of these values were the same. Patients were allowed to switch from one BZRA to another without it interrupting their 'use episodes'. This included switching from a BZD to a Z-drug and vice versa.

\section{Independent variables}

Variables used for statistical prediction of long-term use were determined a priori and included age, sex, geographical residence, residential mobility, socioeconomic status, marriage, concurrent opioid or prescription psychotropic use, comorbidity burden, healthcare usage, time period of first prescription and prescriber characteristics (online supplemental tables A4 and A5). Variables were assessed at baseline; either within 1 year before the index date, at the index date or up to 6 months past the index date (in the case of prescription opioids and other psychotropics, such as antidepressants, antipsychotics and mood stabilisers).

\section{Statistical analysis}

Standard reporting criteria were followed in the approach to logistic regression modelling (online supplemental tables A6 and A7). ${ }^{32}$ Univariate analysis was performed first in the form of simple logistic regression. The multivariable model was constructed to determine the most parsimonious model for prediction of long-term BZRA use defined as $\geq 180$ days in the first episode of use with adjustment of clinically relevant covariates based on previous literature. ${ }^{24}$ Differences between models in their maximum log-likelihood estimation, likelihood ratios and other goodness-of-fit statistics enabled model discrimination. ${ }^{32}$ Multicollinearity and effect-measure modification (ie, interaction effects) were assessed when it was suspected that variables may be either correlated or nonindependent. ${ }^{32}$ In order to perform these diagnostics, the binary dependent variable was first substituted for a linear variable (first-episode duration in days) to conduct a multiple linear regression. Specifically, collinearity was determined to be a model threat if any correlation coefficient in the independent variable correlation matrix was $\geq|0.8|$ or if any variance inflation factor was unreasonably high $(\geq 10)$ while the corresponding tolerance factor was minuscule $(\leq 0.1) .{ }^{33}$ Analyses were assessed at $\mathrm{p}<0.01$ threshold set a priori for statistical significance.

For the multiple logistic regression, 'complete-case analysis' was used because the extent of missing data was too small to justify the need for multiple imputation procedures. ${ }^{34}$ In this study, no claims were excluded on the basis of missing data fields. Only 1568 claims $(<0.01 \%)$ were excluded for being spurious (ie, '0' day/ quantity supply or incredibly high dispensed quantity to day-supply ratio) Furthermore, observed missing data was believed to be missing at random. ${ }^{35}$ The only variable with significant missing data was that of 'prescriber type' ( 38000 missing observations or $17.5 \%$ of final sample).

A subgroup analysis of each of the 17 categories of the Charlson Comorbidity Score was also performed using Z-test of two proportions to describe the specific comorbidities that may contribute to the relationship between Charlson Comorbidity Score and long-term use.

\section{Sensitivity analysis}

To assess the robustness of the primary outcome, six sensitivity analyses (online supplemental tables A8 and A9) were conducted to determine how the proportion of long-term use changed under differing parameter assumptions. ${ }^{36}$ The threshold duration for long-term use was adjusted to values ranging from 60 days to 365 days. Additionally, the episode lapse criteria (ie, prescription gap rule) was changed. While the analysis was not exhaustive for every conceivable combination of these key parameters, the selected values were chosen because 
they were judged to be representative of how peers in the international clinical community may have defined or measured 'long-term use' of BZRA. All data were cleaned and analysed using SAS V.9.4.

\section{RESULTS}

\section{Episodic BZD/Z-drug use}

Study population demographics are presented in table 1 . There were 206933 patients in our cohort representing 931271 unique BZRA dispensations over the 15-year study duration. Over the study period, cohort individuals had a median of three and average of 4.5 BZRA use episodes, respectively. First episodes of use were of a median duration of 20 days (IQR $=10-30$ days). For all use episodes, the median average use duration was 30 days (IQR $=15-111$ days). Evaluation of long-term use revealed that $4.51 \%$ of patients used a BZRA for $\geq 180$-days in their 'first' episode of use. At most, this proportion increased to $9.64 \%$ when a sensitivity analysis of 60 days or greater was used for the definition of 'long-term use' for the first episode of use. However, the proportion of longterm users increased considerably after averaging for all episodes for each user (sensitivity analysis range: 15.6\%$35.1 \%$ ) (online supplemental table A7).

To evaluate treatment duration for insomnia, a sensitivity analysis was performed on only Z-drugs $(n=110663)$, which found similar results (online supplemental tables A9-A12).

\section{Factors predicting long-term first episode use}

Logistic regression analysis revealed that male sex (adjusted OR 1.33, 95\% CI 1.27 to 1.39 ), older age (adjusted OR 2.24, 95\% CI 2.11 to 2.38) and 5.15 (95\% CI 4.81 to 5.52 ) for aged $45-64$ years and $\geq 65$ years, respectively, compared with $<45$ years), receipt of income assistance (adjusted OR 1.68, 95\% CI 1.55 to 1.81 ), previous non-BZRA psychotropic (adjusted OR 1.93, 95\% CI 1.83 to 2.02) or opioid use (adjusted OR 1.16, 95\% CI 1.11 to 1.22), high comorbidity (Charlson Comorbidity Index 1 and $\geq 2$, adjusted OR $1.11,95 \%$ CI 1.04 to 1.17 ) and $1.43,95 \%$ CI 1.32 to 1.55 , respectively), high healthcare resource use (resource utilisation band of 4 and 5 , adjusted OR $1.15,95 \%$ CI 1.07 to 1.23 and $1.46,95 \%$ CI 1.33 to 1.60 , respectively), first prescription from psychiatrist (adjusted OR 2.11, 95\% CI 1.93 to 2.32) and receipt of first prescription after 2006 (2006-2011, adjusted OR $1.74,95 \%$ CI 1.64 to 1.85 ; 2011-2015, adjusted OR 2.99, $95 \%$ CI 2.80 to 3.18 ), were all predictive of long-term use of $\geq 180$ days in the first episode. Rural residence (adjusted OR 1.10, 95\% CI 1.04 to 1.15) and high residential mobility (adjusted OR 1.14, 95\% CI 1.08 to 1.21 ) were also associated with a higher risk of long-term use in the first episode. Married status was associated with a lower risk of meeting the long-term use definition (adjusted OR $0.79,95 \%$ CI 0.76 to 0.83 ). These findings were also replicated in the sensitivity analysis restricted to Z-drug users.
Both the crude and adjusted ORs are presented for the full cohort in table 2 .

A subanalysis of the higher comorbidity scores in the long-term user groups shows that this relationship was mainly driven by cardiovascular diseases, diabetes and dementia (table 3). Proportions for these particular diagnoses were 2-5 times higher in the long-term user group, with the greatest difference existing for dementia (long term; $8.5 \%$ vs short term; $1.5 \%$ ). A sensitivity analysis was performed changing the definition of incident user to no receipt of BZRA prescription in the 3 years prior to the first BZRA prescription. No change in results were found.

\section{DISCUSSION}

This study found approximately $4.5 \%$ of the full cohort and $7.4 \%$ of the Z-drug cohort were 'long-term' firstepisode users according to the best available evidencebased consensus definition of 180 days. ${ }^{24}$ Restricting the analysis to Z-drug use showed that the frequency of longterm use was higher than that of the main cohort. Practice guidelines typically recommend a shorter duration of use for Z-drugs in the treatment of insomnia (range of $\leq 2-6$ weeks) $)^{37-39}$ compared with BZD for anxiety disorder (up to $\leq 12$ weeks depending on indication).$^{40-42}$ Therefore, these results suggest greater disparity from practice guidelines in the case of Z-drug use for insomnia. Of note, more recent insomnia guidelines have recognised that while non-drug alternatives have a favourable safety profile, these interventions may be difficult to achieve for certain populations, which could explain the deviation between practice recommendations and real-world use of these agents. $^{38}$

The proportion of patients who met criteria for 'longterm' use after accounting for all of their use-episodes (ie, rather than just the first episode of use) was approximately 3.5 times higher than the proportion of patients meeting criteria after only their first episode of use. These results may indicate that repeated episodes of BZRA use may be associated with a higher risk of being exposed to a BZRA for a duration of $\geq 180$ days in one episode. An area of future research is to examine whether repeated episodes of BZRA use is associated with progression to long-term use as demonstrated in a previous study that observed the number of episodes of dispensing in the first month was a significant predictor of the total duration of dispensing in the later period. ${ }^{43}$ Of note, the majority of people with repeated use still only take BZRAs for intermittent, shortterm periods. Furthermore, confounding variables such as age and accrued comorbidity over time may influence the risk of future long-term use in some patients. Nonetheless, these results support the observed difficulty in deprescribing once BZRA use has become chronic, which has also been reported in previous literature. ${ }^{44}$ Lastly, other clinical considerations such as risk of protracted withdrawal symptoms, risk of rebound insomnia and/ or anxiety, severity of indication, patient dissatisfaction, limited alternate drug and non-drug interventions, or 
Table 1 Characteristics of BZRA users by first use episode duration

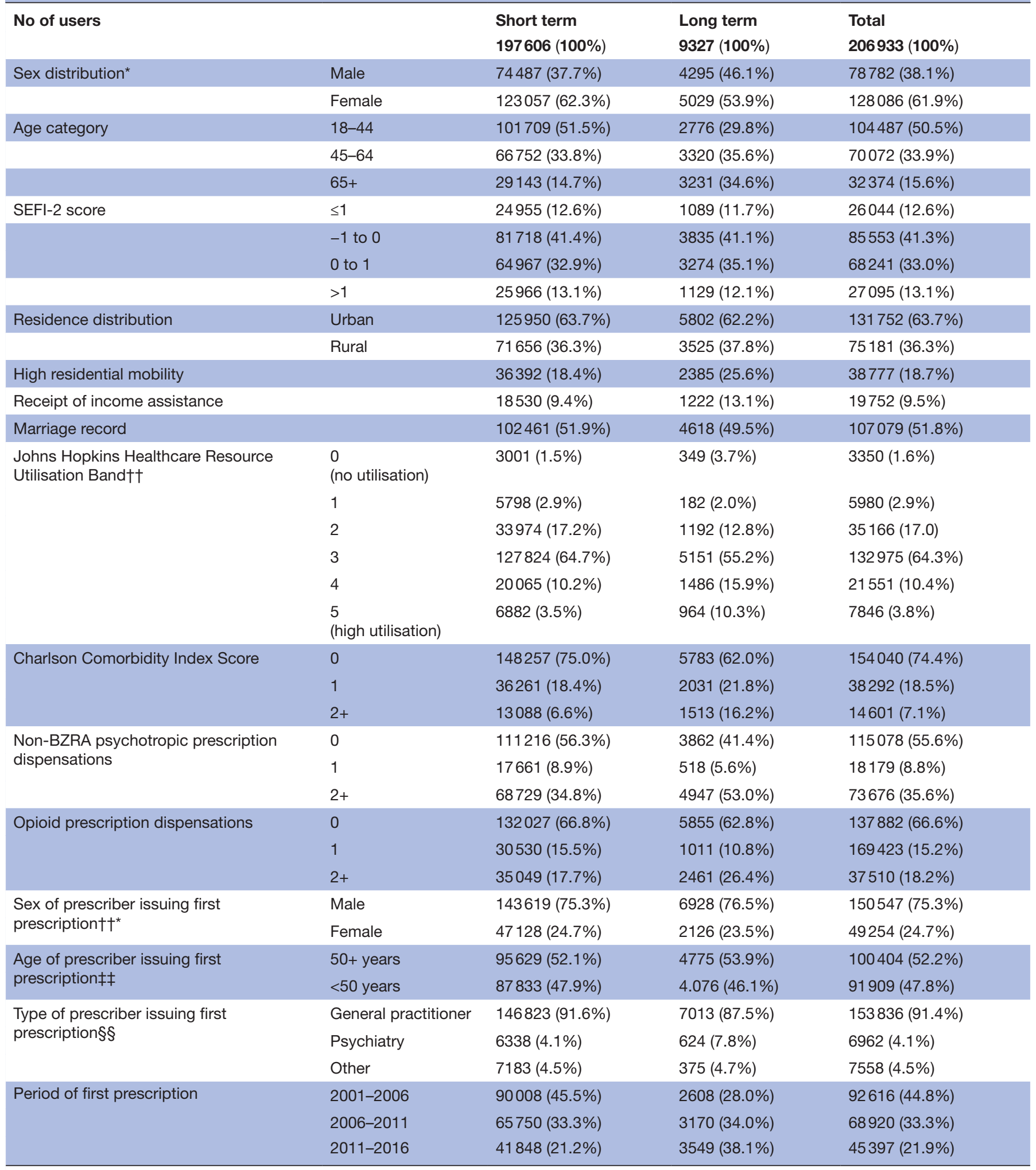

${ }^{*} \mathrm{~N}=197544$ (short-term users); $\mathrm{N}=9324$ (long-term users); $\mathrm{N}=206868$ (total users). $\dagger \mathrm{N}=197544$ (short-term users); $\mathrm{N}=9324$ (long-term users); $\mathrm{N}=206868$ (total users). $\ddagger \mathrm{N}=183462$ (short-term users); $\mathrm{N}=8851$ (long-term users); $\mathrm{N}=192313$ (total users). $\S \mathrm{N}=160344$ (short-term users); $\mathrm{N}=8012$ (long-term users); $\mathrm{N}=168356$ (total users). BZRA, benzodiazepine receptor agonist; SEFI-2, socioeconomic factor index. 


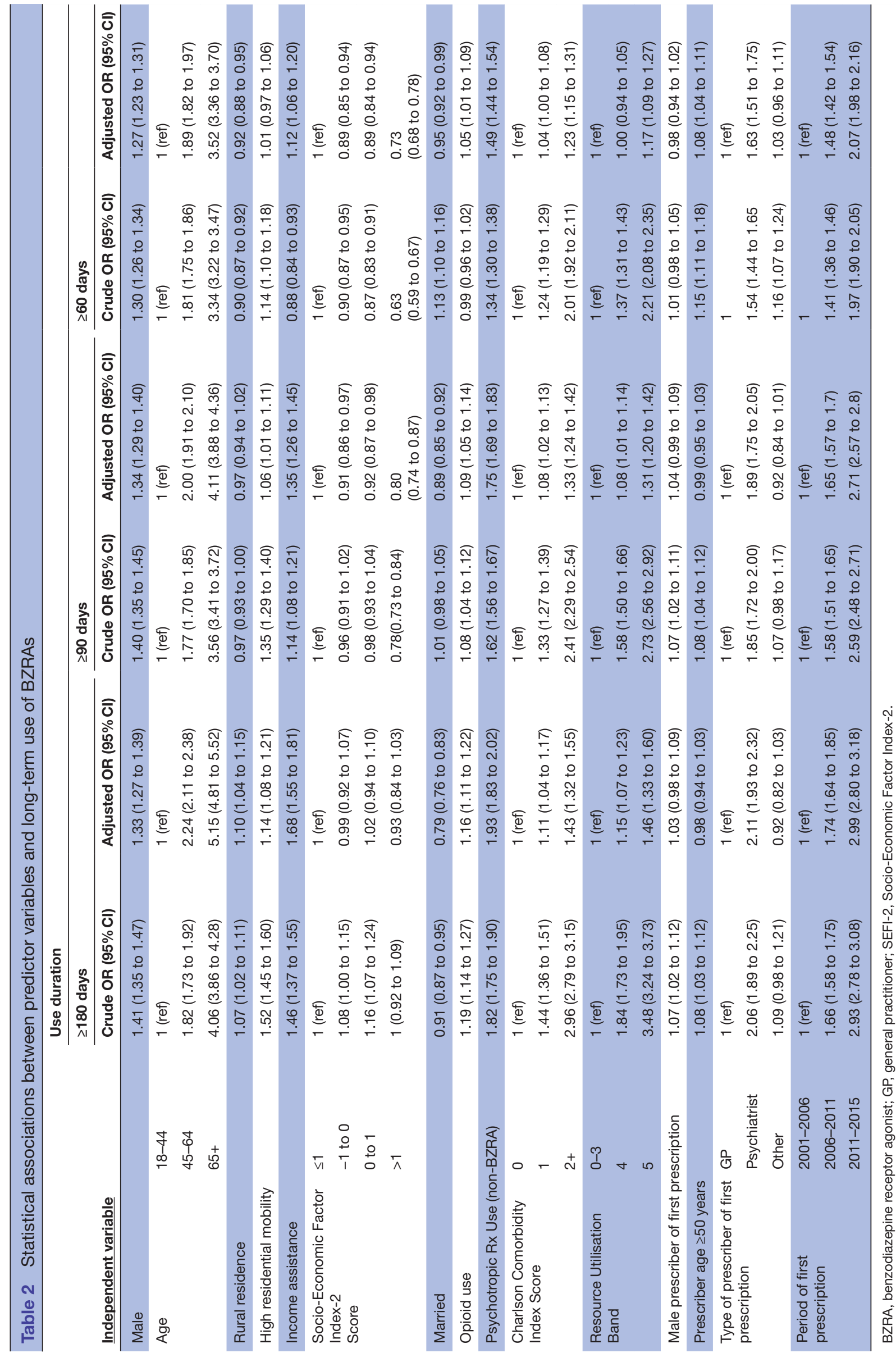


Table 3 Frequency of Charlson Comorbidity Group diagnoses by first use episode duration for BZD/Z-Drug cohort

\begin{tabular}{|c|c|c|c|}
\hline Charlson diagnosis & $\begin{array}{l}\text { Short-term 'first-episode' users } \\
(\mathrm{n}=197606)\end{array}$ & $\begin{array}{l}\text { Long-term 'first-episode' } \\
\text { users ( } n=9327)\end{array}$ & Z-test of two proportions \\
\hline Myocardial infarction & 2474 (1.3\%) & 281 (3.0\%) & $P<0.01$ \\
\hline Congestive heart failure & $3943(2.0 \%)$ & $628(6.7 \%)$ & $P<0.01$ \\
\hline Peripheral vascular disease & $2367(1.2 \%)$ & $256(2.7 \%)$ & $P<0.01$ \\
\hline Cerebrovascular disease & $3690(1.9 \%)$ & $544(5.8 \%)$ & $P<0.01$ \\
\hline Dementia & 2928 (1.5\%) & 796 (8.5\%) & $P<0.01$ \\
\hline COPD & $23064(11.7 \%)$ & $1163(12.5 \%)$ & $\mathrm{P}=0.02$ \\
\hline $\begin{array}{l}\text { Connective tissue/rheumatic } \\
\text { disease }\end{array}$ & $2793(1.4 \%)$ & $222(2.4 \%)$ & $P<0.01$ \\
\hline Peptic ulcer disease & $2140(1.1 \%)$ & $114(1.2 \%)$ & $P=0.20$ \\
\hline Mild liver disease & $2406(1.2 \%)$ & $135(1.4 \%)$ & $P=0.05$ \\
\hline Moderate/severe liver disease & $341(0.1 \%)$ & $28(0.0 \%)$ & $P<0.01$ \\
\hline Uncomplicated diabetes & $14131(7.2 \%)$ & $1099(11.8 \%)$ & $P<0.01$ \\
\hline Complicated diabetes & $1611(0.8 \%)$ & $252(2.7 \%)$ & $P<0.01$ \\
\hline Paraplegia and hemiplegia & $794(0.4 \%)$ & $136(1.5 \%)$ & $P<0.01$ \\
\hline Renal disease & $1858(0.9 \%)$ & $238(2.6 \%)$ & $P<0.01$ \\
\hline Cancer & $829(0.4 \%)$ & $64(0.1 \%)$ & $P<0.01$ \\
\hline Metastatic carcinoma & $64(0.0 \%)$ & $13(0.0 \%)$ & $P<0.01$ \\
\hline HIV/AIDS & $50(0.0 \%)$ & $10(0.0 \%)$ & $P<0.01$ \\
\hline
\end{tabular}

BZD, benzodiazepines; COPD, chronic obstructive pulmonary disease.

interference with another prescriber's decisions likely undermine potential deprescribing efforts.

Older age and female sex have also been identified in previous studies as being associated with long-term use. ${ }^{45-51}$ While we found females to have greater representation in all patterns of BZRA use, we found males were more specifically predictive of long-term use after the first episode of use.$^{52-54}$ As with almost all of the previously published studies, older age was strongly associated with long-term BZRA use. ${ }^{51-55}$ It should be noted that older individuals may have had a greater opportunity to be exposed to BZRA use.

As supported by previous evidence, income assistance was associated with long-term BZRA use. ${ }^{46}$ Our study also found frequent moving, unmarried status and rural residence to be associated with increased odds of longterm use. Frequency of moving and income assistance could be a proxy for general life stability. ${ }^{5758}$ Rural residence may have a small effect on longer-term BZRA use due to the relative limitations of timely scheduled follow-up, which may necessitate prescriptions of greater quantity or for longer periods. Another study also found rural adults to be at higher odds of inappropriate BZD use . ${ }^{59}$

Healthcare use and the presence of various physical illnesses have been consistent predictors of long-term BZRA use. ${ }^{47495060}$ In this study, as both of these variables increased, so did the odds of long-term use. We speculate that the positive relationship between these two indices and long-term use may be partially explained by unmeasured 'health' anxiety or associated mental health issues arising secondary to physical comorbidities or by additional disruptive effects of physical illness on sleep.

The Charlson Comorbidity Score findings were not surprising given the relatively higher proportion of older adults in the long-term use group. Nonetheless, the greater degree of BZRA exposure among those patients with dementia is of concern given the risk of BZD use in this population. ${ }^{9}$ Similar to previous studies, prescriptions for an opioid or a psychotropic agent, such as antidepressants, antipsychotics or mood stabilisers, during the baseline period were modestly predictive for future long-term use. 485254565861 Those having received a nonBZD prescription agent for a psychiatric disorder could be expected to have had greater disease severity on average than those BZRA users who did not receive such treatment early on.

An unexpected finding was the increased odds of longterm use associated with the more recent time period of the first prescription. This is contrary to what may be expected from cumulative knowledge on BZRA and the long-standing emphasis on short-term use advised in guidelines and clinical literature. This finding may reflect the growing awareness that BZRAs should not be used as a first-line treatment resulting in only those who have not responded to other alternatives to be more likely to receive BZRAs long-term.

This study has a number of strengths. This study used a large administrative data source that were near complete in their coverage of the study population's prescription 
drug dispensations and healthcare contact. Application of cohort inclusion and exclusion criteria in a carefully constructed new user longitudinal design limited confounding and bias to the extent possible. Multiple sensitivity analyses on the main outcome measure, the duration of BZRA use measurement method and the association between the independent and dependent variables for two cohorts reduced quantitative bias to increase confidence in the results.

A few important limitations should be acknowledged. First, administrative data are prone to some misclassification of variables. For instance, diagnostic criteria for cohort case inclusion and exclusion will differ in their true sensitivity and specificity, regardless of prior validation of case definitions. Drugs used during any hospitalisations were not available and was assumed to be continued BZD exposure. As all independent variables were only measured cross-sectionally before or at the time of the first prescription of the first use episode, the logistic regression model was only predictively valid for the first use episode duration and not users' average episode duration. Since DPIN only captures the days supply provided, it is possible that not all of the medication was actually taken by the patient. However, this study was able to provide insight into the prescribing practices of BZD that are filled in the pharmacy in this population. Our study did not evaluate the extent of concurrent use of multiple BZD or other psychiatric diagnoses such as substance use disorder. The databases also do not capture participation in psychological interventions such as cognitive behavioural therapy. Moreover, while the databases are able to link several data on health information regardless of age and coverage, they do not capture other potential confounding factors such as education status and ethnicity. This study was done in a setting where there is a universal healthcare system and medication costs are covered for all Manitobans after an income-based deductible is met every year. As a result, findings may be generalisable to similar settings. Future research should aim to examine the association of repeat exposure to BZRA and risk of chronic use. Future research could also examine specific benzodiazepine type and formulations on risk of long-term use.

\section{CONCLUSION}

Prescribing of BZRAs was used for less than 6 months duration for the majority of individuals with a prior history of anxiety, depression or insomnia. However, the proportion of long-term use among new users was up to one in three based on the average of all episodes of use, warranting future research in this area. Patients who are male, of older age, are socially or financially deprived, have poor physical health, use opioids or other psychotropic agents and are frequent consumers of healthcare resources are more likely to use BZRA long-term after their first prescription. Future research could be done to explore whether these factors need to be considered at the point of prescribing in clinical practice.

Acknowledgements The authors wish to acknowledge Dr Sheryl Zelenitsky for her helpful comments on earlier drafts of this manuscript. The authors acknowledge the Manitoba Centre for Health Policy for use of data contained in the Manitoba Population Research Data Repository under Research Ethic Board approval HS20498 (HIPC\#2016/2017-062). The results and conclusions are those of the authors and no official endorsement by the Manitoba Centre for Health Policy, Manitoba Health, or other data providers is intended or should be inferred.

Contributors JB is guarantor and contributed to the conception, design, acquisition of data, analysis and writing of the manuscript. DJ contributed to the analysis, interpretation and writing of the manuscript. SA-S contributed to the interpretation and writing of the manuscript. DC contributed to the interpretation and analysis of the study. ME contributed to the interpretation and writing of the study. AS contributed to the interpretation and writing of the study. CL contributed to the conception, design, interpretation and writing of the manuscript.

Funding This work was supported by the College of Pharmacy at the University of Manitoba. Additional student funding for JB was granted by the Provincial Government of Manitoba in the form of a Manitoba Graduate Scholarship stipend.

Disclaimer Funding sources had no role in the conduct of research and/or preparation of the article.

Competing interests None declared.

Patient and public involvement statement We have a patient advisory group who provided feedback on the dissemination of research findings.

Patient consent for publication Not applicable.

Ethics approval Access to the data for this project was approved by the University's Health Research Ethics Board (HREB, registration number H2017:052 (HS20498) and the Health Information Privacy Committee (HIPC, no. 2016/201762) of the provincial government. Consent for this study was not required by HREB given the retrospective nature of the study and data agreements in place through HIPC.

Provenance and peer review Not commissioned; externally peer reviewed.

Data availability statement All data relevant to the study are included in the article or uploaded as online supplemental information. Data used in this article were derived from administrative health and social data as a secondary use. The data were provided under specific data sharing agreements only for approved use at MCHP. The original source data is not owned by the researchers or MCHP and as such cannot be provided to a public repository.

Supplemental material This content has been supplied by the author(s). It has not been vetted by BMJ Publishing Group Limited (BMJ) and may not have been peer-reviewed. Any opinions or recommendations discussed are solely those of the author(s) and are not endorsed by BMJ. BMJ disclaims all liability and responsibility arising from any reliance placed on the content. Where the content includes any translated material, BMJ does not warrant the accuracy and reliability of the translations (including but not limited to local regulations, clinical guidelines, terminology, drug names and drug dosages), and is not responsible for any error and/or omissions arising from translation and adaptation or otherwise.

Open access This is an open access article distributed in accordance with the Creative Commons Attribution Non Commercial (CC BY-NC 4.0) license, which permits others to distribute, remix, adapt, build upon this work non-commercially, and license their derivative works on different terms, provided the original work is properly cited, appropriate credit is given, any changes made indicated, and the use is non-commercial. See: http://creativecommons.org/licenses/by-nc/4.0/.

ORCID iD

Christine Leong http://orcid.org/0000-0003-0033-6877

\section{REFERENCES}

1 O'brien CP. Benzodiazepine use, abuse, and dependence. J Clin Psychiatry 2005;66 Suppl 2:28-33.

2 Dell'osso B, Lader M. Do benzodiazepines still deserve a major role in the treatment of psychiatric disorders? a critical reappraisal. Eur Psychiatry 2013;28:7-20.

3 Moore N, Pariente A, Bégaud B. Why are benzodiazepines not yet controlled substances? JAMA Psychiatry 2015;72:110-1. 
4 Sirdifield C, Anthierens S, Creupelandt H, et al. General practitioners' experiences and perceptions of benzodiazepine prescribing: systematic review and meta-synthesis. BMC Fam Pract 2013;14:191.

5 López-Muñoz F, Álamo C, García-García P. The discovery of chlordiazepoxide and the clinical introduction of benzodiazepines: half a century of anxiolytic drugs. J Anxiety Disord 2011;25:554-62

6 Lader M, Tylee A, Donoghue J. Withdrawing benzodiazepines in primary care. CNS Drugs 2009;23:19-34.

7 Xing D, Ma XL, Ma JX, et al. Association between use of benzodiazepines and risk of fractures: a meta-analysis. Osteoporos Int 2014;25:105-20.

8 Rapoport MJ, Lanctôt KL, Streiner DL, et al. Benzodiazepine use and driving: a meta-analysis. J Clin Psychiatry 2009;70:663-73.

9 Pariente A, de Gage SB, Moore N, et al. The benzodiazepinedementia disorders link: current state of knowledge. CNS Drugs 2016;30:1-7.

10 Perlis RH, Ostacher MJ, Miklowitz DJ, et al. Benzodiazepine use and risk of recurrence in bipolar disorder: a STEP-BD report. J Clin Psychiatry 2010;71:194-200.

11 Lai S-W, Lai H-C, Lin C-L, et al. Zopiclone use associated with increased risk of acute pancreatitis: a case-control study in Taiwan. Int J Clin Pract 2015;69:1275-80.

12 Dodds TJ. Prescribed benzodiazepines and suicide risk: a review of the literature. Prim Care Companion CNS Disord 2017;19. doi:10.4088/PCC.16r02037. [Epub ahead of print: 02 Mar 2017].

13 Rodriguez-Roisin R, Garcia-Aymerich J. Should we exercise caution with benzodiazepine use in patients with COPD? Eur Respir J 2014;44:284-6.

14 Brandt J, Leong C. Benzodiazepines and Z-drugs: an updated review of major adverse outcomes reported on in epidemiologic research. Drugs R D 2017;17:493-507.

15 El-Guebaly N, Sareen J, Stein MB. Are there guidelines for the responsible prescription of benzodiazepines? Can J Psychiatry 2010;55:709-14.

16 Bendtsen P, Hensing G, McKenzie L, et al. Prescribing benzodiazepines--a critical incident study of a physician dilemma. Soc Sci Med 1999;49:459-67.

17 Paquin AM, Zimmerman K, Rudolph JL. Risk versus risk: a review of benzodiazepine reduction in older adults. Expert Opin Drug Saf 2014;13:919-34.

18 Alessi-Severini S, Bolton JM, Enns MW, et al. Use of benzodiazepines and related drugs in Manitoba: a population-based study. CMAJ Open 2014;2:E208-16.

19 Berman E, Eyal S, Marom E. Trends in utilization of benzodiazepine and Z-drugs in Israel. Pharmacoepidemiol Drug Saf 2017;26:1555-60.

20 Takano A, Ono S, Yamana $\mathrm{H}$, et al. Factors associated with long-term prescription of benzodiazepine: a retrospective cohort study using a health insurance database in Japan. BMJ Open 2019;9:e029641.

21 Hata T, Kanazawa T, Hamada T, et al. What can predict and prevent the long-term use of benzodiazepines? J Psychiatr Res 2018:97:94-100.

22 Charlson ME, Pompei P, Ales KL, et al. A new method of classifying prognostic comorbidity in longitudinal studies: development and validation. J Chronic Dis 1987;40:373-83. doi:10.1016/00219681(87)90171-8

23 Bramness JG, Sexton JA. The basic pharmacoepidemiology of benzodiazepine use in Norway 2004-9. Nor Epidemiol 2011;21:35-41. doi:10.5324/nje.v21i1.1423

24 Kurko TAT, Saastamoinen LK, Tähkäpää S, et al. Long-term use of benzodiazepines: definitions, prevalence and usage patterns - a systematic review of register-based studies. Eur Psychiatry 2015;30:1037-47.

25 Willems IAT, Gorgels WJMJ, Oude Voshaar RC, et al. Tolerance to benzodiazepines among long-term users in primary care. Fam Pract 2013;30:404-10.

26 Public Health Agency of Canada, Government of Canada. Report from the Canadian chronic disease surveillance system: mood and anxiety disorders in Canada, 2016. Available: http:// healthycanadians.gc.ca/publications/diseases-conditionsmaladies-affections/mental-illness-2015-maladies-mentales/indexeng.php

27 Manitoba Centre for Health Policy, Department of Community Health Sciences $U$ of M. Concept: mood and anxiety disorders - measuring prevalence, 2015. Available: http://mchp-appserv.cpe.umanitoba.ca/ viewConcept.php?conceptID=1391\#a_references [Accessed $21 \mathrm{Feb}$ 2017]

$28 \mathrm{MCHP}$. University of Manitoba - manitoba centre for health policy - glossary: anxiety /anxiety states, 2010. Available: http://mchpappserv.cpe.umanitoba.ca/viewDefinition.php?definitionID=102267 [Accessed 11 Jul 2018].
29 Chung K-F, Yeung W-F, Ho FY-Y, et al. Cross-cultural and comparative epidemiology of insomnia: the diagnostic and statistical manual (DSM), International classification of diseases (ICD) and international classification of sleep disorders (ICSD). Sleep Med 2015;16:477-82.

30 Lader M. Benzodiazepine harm: how can it be reduced? Br J Clin Pharmacol 2014;77:295-301.

31 Palmaro A, Boucherie Q, Dupouy J, et al. Immeasurable time bias due to hospitalization in medico-administrative databases: which impact for pharmacoepidemiological studies? Pharmacoepidemiol Drug Saf 2017;26:544-53.

32 Bagley SC, White H, Golomb BA. Logistic regression in the medical literature: standards for use and reporting, with particular attention to one medical domain. J Clin Epidemiol 2001;54:979-85.

33 Rasouliyan L, Miller DP. The Logic and Logistics of Logistic Regression. In: Western users of SAS software 2006. Irvine, CA: Department of Community Health Sciences U of M, 2006: 1-14. https://www.lexjansen.com/wuss/2006/analytics/ANL-Rasouliyan. pdf

34 Schreiber-Gregory DN. Multicollinearity : what is it, why should we care, and how can it be controlled? 2017. Available: https:// analytics.ncsu.edu/sesug/2017/SESUG2017_Paper-160_Final_PDF. pdf

35 Bennett DA. How can I deal with missing data in my study? Aust N Z J Public Health 2001;25:464-9 http://onlinelibrary.wiley.com/doi/

36 Lash TL, Fox MP, MacLehose RF, et al. Good practices for quantitative bias analysis. Int J Epidemiol 2014;43:1969-85

37 Qaseem A, Kansagara D, Forciea MA, et al. Management of chronic insomnia disorder in adults: a clinical practice guideline from the American college of physicians. Ann Intern Med 2016;165:125-33.

38 Sateia MJ, Buysse DJ, Krystal AD, et al. Clinical practice guideline for the pharmacologic treatment of chronic insomnia in adults: an American Academy of sleep medicine clinical practice guideline. $J$ Clin Sleep Med 2017;13:307-49.

39 National Institute for Clinical Excellence. Guidance on the use of zaleplon, zolpidem and zopiclone for the short-term management of insomnia, 2004. Available: https://www.nice.org.uk/guidance/ ta77/resources/guidance-on-the-use-of-zaleplon-zolpidemand-zopiclone-for-the-shortterm-management-of-insomnia2294763557317

40 Bandelow B, Sher L, Bunevicius R, et al. Guidelines for the pharmacological treatment of anxiety disorders, obsessivecompulsive disorder and posttraumatic stress disorder in primary care. Int J Psychiatry Clin Pract 2012;16:77-84.

41 Baldwin DS, Anderson IM, Nutt DJ, et al. Evidence-based pharmacological treatment of anxiety disorders, posttraumatic stress disorder and obsessive-compulsive disorder: a revision of the 2005 guidelines from the British association for psychopharmacology. J Psychopharmacol 2014;28:403-39.

42 Katzman MA, Bleau P, Blier P, et al. Canadian clinical practice guidelines for the management of anxiety, posttraumatic stress and obsessive-compulsive disorders. BMC Psychiatry 2014;14 Suppl 1:S1-83.

43 Islam MM. Pattern and probability of dispensing of prescription opioids and benzodiazepines among the new users in Australia: a retrospective cohort study. BMJ Open 2019;9:e030803.

44 Sirdifield C, Chipchase SY, Owen S, et al. A systematic review and meta-synthesis of patients' experiences and perceptions of seeking and using benzodiazepines and Z-Drugs: towards safer prescribing. Patient 2017:10:1-15.

45 Simon GE, VonKorff M, Barlow W, et al. Predictors of chronic benzodiazepine use in a health maintenance organization sample. $J$ Clin Epidemiol 1996;49:1067-73.

46 Alessi-Severini S, Bolton JM, Enns MW, et al. Sustained use of benzodiazepines and escalation to high doses in a Canadian population. Psychiatr Serv 2016;67:1012-8.

47 Cunningham CM, Hanley GE, Morgan S. Patterns in the use of benzodiazepines in British Columbia: examining the impact of increasing research and guideline cautions against long-term use. Health Policy 2010;97:122-9.

48 Soumerai SB, Simoni-Wastila L, Singer C, et al. Lack of relationship between long-term use of benzodiazepines and escalation to high dosages. Psychiatr Serv 2003;54:1006-11.

49 Luijendijk HJ, Tiemeier H, Hofman A, et al. Determinants of chronic benzodiazepine use in the elderly: a longitudinal study. $\mathrm{Br} J$ Clin Pharmacol 2008;65:593-9.

50 Jorm AF, Grayson D, Creasey $\mathrm{H}$, et al. Long-term benzodiazepine use by elderly people living in the community. Aust N Z J Public Health 2000;24:7-10.

51 Kurko T, Saastamoinen LK, Tuulio-Henriksson A, et al. Trends in the long-term use of benzodiazepine anxiolytics and hypnotics: a 
national register study for 2006 to 2014. Pharmacoepidemiol Drug Saf 2018;27:674-82.

52 Fride Tvete I, Bjørner T, Skomedal T. Risk factors for excessive benzodiazepine use in a working age population: a nationwide 5-year survey in Norway. Scand J Prim Health Care 2015;33:252-9.

53 Kjosavik SR, Ruths S, Hunskaar S. Use of addictive anxiolytics and hypnotics in a national cohort of incident users in Norway. Eur J Clin Pharmacol 2012;68:311-9.

54 Fang S-Y, Chen C-Y, Chang I-S, et al. Predictors of the incidence and discontinuation of long-term use of benzodiazepines: a populationbased study. Drug Alcohol Depend 2009;104:140-6.

55 Olfson M, King M, Schoenbaum M. Benzodiazepine use in the United States. JAMA Psychiatry 2015;72:136-42.

56 Andersen ABT, Frydenberg M. Long-term use of zopiclone, zolpidem and zaleplon among Danish elderly and the association with sociodemographic factors and use of other drugs. Pharmacoepidemiol Drug Saf 2011;20:378-85.
57 Scott KM, Wells JE, Angermeyer M, et al. Gender and the relationship between marital status and first onset of mood, anxiety and substance use disorders. Psychol Med 2010;40:1495-505.

58 Patten SB, Williams JV, Lavorato DH, et al. Pharmacoepidemiology of benzodiazepine and sedative-hypnotic use in a Canadian general population cohort during 12 years of follow-up. Can J Psychiatry 2010;55:792-9.

59 Mattos MK, Sereika SM, Naples JG, et al. Differences in benzodiazepine receptor agonist use in rural and urban older adults. Drugs Real World Outcomes 2016;3:289-96.

60 Manthey L, van Veen T, Giltay EJ, et al. Correlates of (inappropriate) benzodiazepine use: the Netherlands study of depression and anxiety (NESDA). Br J Clin Pharmacol 2011;71:263-72.

61 Sakshaug S, Handal M, Hjellvik V, et al. Long-term use of Zhypnotics and co-medication with benzodiazepines and opioids. Basic Clin Pharmacol Toxicol 2017;120:292-8. 